\title{
Hospital planning for weapons of mass destruction incidents
}

\author{
Perry RW, Lindell MK*
}

School of Public Affairs, Arizona State University, Tempe, Arizona 852870603, USA

*Hazard Reduction and Recovery Center, Texas A \& M University, College Station, Texas-ss77843, USA

\section{Correspondence:}

Ronald W. Perry,

E-mail: ron.perry@asu.edu

Received : 17-05-05

Review completed : 28-05-05

Accepted : :08-06-05

PubMed ID

J Postgrad Med 2006;52:116-20

\begin{abstract}
As terrorists attacks increase in frequency, hospital disaster plans need to be scrutinized to ensure that they take into account issues unique to weapons of mass destruction. This paper reports a review of the literature addressing hospital experiences with such incidents and the planning lessons thus learned. Construction of hospital disaster plans is examined as an ongoing process guided by the disaster planning committee. Hospitals are conceived as one of the components of a larger community disaster planning efforts, with specific attention devoted to defining important linkages among response organizations. This includes the public health authorities, political authorities, prehospital care agencies, and emergency management agencies. A review is completed of six special elements of weapons of mass destruction incidents that should be addressed in hospital disaster plans: incident command, hospital security, patient surge, decontamination, mental health consequences, and communications. The paper closes with a discussion of the importance of training and exercises in maintaining and improving the disaster plan.
\end{abstract}

KEY WORDS: Hospital disaster plans, mass casualties, terrorism, weapons of mass destruction

\begin{abstract}
Ofosp ospitals are the community locus of care for emergencies and disasters. Whether the crisis is for an individual (cardiac or trauma), a small group (vehicular accidents), or the entire community (natural or technological disasters), hospitals deliver both emergency and extended treatment to victims. Furthermore, it is a long tradition that virtually all hospitals maintain "disaster plans" that address protocols and procedures to be implemented when unusual demands are placed on the facility. Typically, there are internal disaster plans dealing with threats arising inside the institution, such as loss of electric power or failure of centralized oxygen systems-and external disaster plans which address the strategy to be used when events such as fires, chemical plant releases, or natural disasters that create large patient surges. ${ }^{[1]}$
\end{abstract}

With the rise of worldwide terrorism, there has been renewed concern with hospital preparedness for events that involve the use of weapons of mass destruction (WMD), whose agents may be chemical, biological, radiological, nuclear, or explosive (CBRNE). Such terrorist-generated events pose a variety of special challenges for hospital emergency planning. They combine features of internal and external disaster plans for hospitals because the institutions themselves may be impacted in a variety of ways, including contamination, loss of off duty staff, and loss of access to critical pharmaceuticals, equipments, and supplies. There is usually no forewarning. In addition to creat- ing very large patient surge, such incidents also create a need for special protection for hospital staff, decontamination for patients, patient isolation space, and special internal management processes.

The purpose of this paper is to examine selected aspects of hospital disaster preparedness that are attendant to terrorist incidents. These are distinct from natural or technological disasters (products of natural or man-made forces) because terrorists intend harm. Although many emergency functions are the same for each type of event, terrorist incidents require special attention because they usually generate mass casualties, potentially use exotic agents, and are known to attack both citizens and emergency responders and facilities. The emphasis is on WMD incidents involving chemical, biological, or radiological incidents, in which injuries may include physical and psychological trauma as well as chemical or radiological injuries and contamination. The goal is to address selected issues rather than to provide a comprehensive overview of hospital disaster planning; a basic disaster plan is assumed. ${ }^{[2]}$ The presentation begins with hospital preparedness and the general disaster plan. Then the importance and nature of community linkages for successful response is discussed. Following this, special WMD event-related needs are identified for hospital disaster plans. The paper closes with a discussion of the roles of education, training, and exercises in maintaining an accept- 
able level of preparedness.

\section{Disaster preparedness and plans}

Disaster preparedness refers to the readiness of an institution to constructively react to events while reducing the negative consequences for the health and safety of individuals, as well as the integrity and functioning of physical structures and systems. The achievement of preparedness takes place through a process of planning, training, and implementation, accompanied by the acquisition of resources to support active response. ${ }^{[3]}$ The response measures and protocols generated in the planning process and rehearsed via training and exercises are documented in the written plan. In this way, written plans become dynamic documents, to be revised and changed as the threat changes and the system for detecting and responding to the threat changes. ${ }^{[4]}$

A critical step in achieving preparedness rests in establishing a hospital disaster planning committee or group. This group drives the planning process and maintains it. It should be a permanent committee with regular meetings and a chairperson (usually the institution's risk manager). It should include broad representation from the institution, including the medical staff, administration, nursing staff, infection control, emergency department, security, communications, public relations, laboratory/radiology, engineering and maintenance, and medical records and admissions. ${ }^{[5]}$ It is also desirable to include liaison representatives to prehospital care organizations, ambulance services, regional hospital associations, local public health agencies, coroners (medical examiners), local police departments, and local political and disaster management authorities. The objective is to create a committee that fully understands all dimensions of hospital function and capabilities, and to establish access to specialists possessing expertise regarding threats and knowledge of community plans and resources.

Numerous surveys of hospitals in the United States, ${ }^{[6]}$ Canada, ${ }^{[7]}$ India, ${ }^{[8]}$ Japan, ${ }^{[9]}$ China, ${ }^{[10]}$ and Israel ${ }^{[11]}$ have reported low levels of preparedness for WMD terrorist incidents. These findings underscore that, to achieve preparedness, continuing attention to planning process is required. The disaster planning committee is the logical setting to achieve such attention. To insure attention to WMD capabilities, a WMD planning officer should be a designated. This move focuses responsibility and accountability for leading the task of tracking developments regarding recognition, patient management, treatment, and record-keeping connected with WMD agents, and translating that information into functional protocols.

Linkages with the community

The achievement of WMD preparedness is dependent on the recognition that such incidents are simultaneously complex and large. Internationally, political authorities have emphasized the development of community emergency plans that address not just natural and technological disasters, but also terrorist attacks. ${ }^{[12]}$ Although historically, hospitals have only marginally participated in such planning ${ }^{[13]}$ the effective address of WMD incidents demands much fuller participation. The prospect of mass casualties accompanied by significant destruction of community resources requires cooperation between hospitals as well as between hospitals and organizations that deliver local emergency management, prehospital care, law enforcement, public health services, and handling of the deceased.

The longstanding pattern of mutual aid agreements among local fire departments and law enforcement departments forms an important model for hospitals. Such agreements address sharing of personnel, resources, and equipment designed to forestall situations that may overwhelm the resources of a single institution. Bradley ${ }^{[14]}$ indicates that while patient load can be managed to a certain extent when movement to hospitals is controlled by ambulance services, victim self-referral is more common in terrorist incidents, leading patients to hospitals nearest the incident site. This phenomenon creates the conditions for overload at some institutions, whereas others may have no or few patients. Mutual aid agreements and preplanning allow for systematic redistribution of patients, pharmaceuticals, equipment, medical staff, or support staff to relieve overtaxed hospitals.

Connecting hospitals to the larger community through the mutual planning process also is an important priority in WMD preparedness. Virtually, worldwide, local governments and emergency management authorities are engaging in intense and continuing development of community terrorism response plans. ${ }^{[15]}$ These plans typically contain details of the government response (including resource distribution) for the full range of disasters and terrorist incidents. Through participation in such plans, hospitals learn the expectations of authorities and simultaneously can educate authorities on hospital capabilities and guide community plans to more realistically accommodate hospital needs. For example, law enforcement agencies are usually part of community planning, and this planning forum offers a setting in which hospitals can address potential external security needs. Similarly, community disaster planning is the place for dialog regarding special expertise and equipment (e.g., for decontamination or offsite treatment facilities) that may be required by hospitals for WMD casualties. In some communities, prehospital care is provided by government organizations (often through fire departments or special agencies), whereas other communities rely on private organizations (such as ambulance services). Without regard to affiliation, these agencies participate in community disaster plans. Thus, by participating in the planning process, hospitals can guide prehospital treatment (to match established medical protocols), influence triage of patients to different facilities by types of injury, and shape patient loads through identifying priorities for receiving hospitals.

Another important linkage for hospitals is to the public health system, particularly when terrorists use chemical, biological, and radiological agents. These types of linkage must go far beyond the routine "reportable disease" relationship to include consultation on needs for isolation, quarantine, evacuation, treatment protocols, and long-term care. Patient surge may be far too large to accomplish isolation and observation within the confines of hospitals dealing with acute injuries and public health offices possess the legal authority (in most coun- 
tries) to rapidly commandeer appropriate space and personnel. Also, medical quarantine and evacuation orders typically require the participation of public health agencies. Particularly, biological agents may present treatment challenges and require pharmaceuticals that most hospital medical personnel rarely encounter. Public health agencies are better positioned to quickly and effectively link with national government stockpiles of pharmaceuticals and treatment information. Dialog with public health system representatives also creates a forum for addressing the needs for long-term care of victims. Longterm rehabilitation and care demands vary radically across different WMD agents (especially biological and radiological) and hospitals, rather than private physicians, may be forced to assume significant responsibility. Tracking of exposed patients following the Bhopal chemical disaster demanded years of follow-on care. ${ }^{[16]}$ By preplanning such demands with the larger public health system, such needs can be distributed across hospitals, and where possible, the public health system can train private physicians to assume a complementary role.

Finally, the state of medicine relative to many biological, radiological, and chemical threats is such that death tolls are likely to be quite high. Most hospital morgues are small holding areas designed to facilitate transfer of deceased to private funeral services or government medical examiners. Because hospital efforts must focus on patient care, it is important to engage in planning with both medical examiners and public health authorities to arrange effective handling of remains. In some cases, postmortem studies will be needed to confirm agents and inform treatments; and infectious disease risks from bodies form a public health threat. ${ }^{[17]}$ In many countries (e.g., United Kingdom, India, Sweden, Germany, and France), National Governments support centrally maintained and deployable teams for medical and mortuary care; the United States has disaster mortuary and disaster medical assistance teams.

It is not possible to catalog every important linkage with the community in a short space. The important principle is that WMD terrorist incidents require an awareness of the interdependence of institutions. The demands imposed by a WMD terrorist incident are immense and affect virtually all community institutions. No hospital can stand alone in such events; demands quickly outstrip capabilities. Even if hospital facilities are undamaged in an attack, there remains the chance that off-duty personnel can be incapacitated. ${ }^{[18]}$ Collective planning, particularly the integration of hospital plans with those created by local emergency management authorities, is the weakest and yet the most important factor in successful response. ${ }^{[19]}$

\section{Critical hospital disaster plan elements for terrorist incidents} Many detailed templates are available for the development of hospital disaster plans ${ }^{[20]}$ and most hospitals have at least partial plans that may be incomplete with respect to terrorist incidents. ${ }^{[21]}$ The purpose of this discussion is to highlight six features of disaster plans that are often overlooked and critical to successful management of WMD/CBRNE incidents as well as other mass casualty incidents.
Management of the hospital—sometimes called command and control-during any large scale disaster is critical for efficient and effective operations. Following the 2001 earthquake in Gujarat India, it was found that hospitals with preplanned incident management systems were far better able to sustain delivery of medical care both during the crisis and through the aftermath. ${ }^{[22]}$ Most of the hospital community partners in response-fire departments, emergency medical services (EMS), police-routinely use incident command or incident management systems. ${ }^{[23]}$ Hospital adoption of a similar system enables the medical staff to fully integrate their activities with those of supporting agencies as well as to better manage the onslaught of self-referred patients, family members, and other observers who tend to converge on medical facilities. ${ }^{[24]}$ The hospital emergency incident command system has long been available to hospitals and was cited as a "best practice" by the US Occupational Safety and Health Administration. ${ }^{[25]}$ This system provides a predictable chain of management, flexible organization chart, prioritized response checklists, and common language for communication with external agencies. Because WMD incidents may require continuous hospital operations for long periods, it is particularly important that a command center with communication facilities be preplanned. ${ }^{[26]}$ In the United States, the recently implemented National Incident Management System contains a generic incident command component that could also be adapted to hospital needs.

Hospital security represents another critical component of the disaster plan for terrorist incidents. It is common for hospitals to enter "lockdown" mode during disasters to avoid interference with triage and treatment operations and to control patient entry. In addition, during WMD incidents, there are risks of facility contamination and needs for orderly management of extraordinary numbers of patients. Furthermore, there is the potential that terrorists may target the hospital itself in an effort to maximize the impact of their attack. A survey of 30 hospitals in the United States indicated that only one reported awareness of secondary terrorist attacks on emergency care givers and the consequent need for armed protection. ${ }^{[27]}$ Most hospital security is provided by private guard forces and tends to be quickly overtaxed during disaster incidents. To appropriately manage these demands and to provide protection against attack, it is important to plan for supplementation by local police forces.

The hospital's capacity to manage patient surge is a critical target for WMD disaster plans. Large numbers of injuries and deaths are characteristic of WMD incidents; the 1995 sarin attack in the Tokyo subway-small among terrorism attacksproduced nearly 6000 injured. ${ }^{[28]}$ Explicit planning is required to quickly expand patient capacity through restructuring the existing bed space and the incorporation of "hasty treatment space" onsite (hallways, sheltered parking) and offsite (adjacent buildings, public shelters). ${ }^{[29]}$ Furthermore, biological and chemical agents often require patient isolation and observation, which demands still more capacity. ${ }^{[30]}$ Primary and secondary patient triage also require appropriate space. Depending on severity of injury and ambulatory status, any hospital's 
ability to expand has defined limits. Space can sometimes be created through early discharge of in-patients; following the 2001 attack on the US Pentagon, Inova Health System's four hospitals in Virginia made available 343 beds, accounting for $25 \%$ of their capacity. ${ }^{[31]}$ For WMD incidents it is important to calculate the expansion capacity in relation with minimum acceptable patient care standards. In the response process, successful adherence to this capacity may depend on the effectiveness of preplanned mutual aid agreements with other health care facilities. Finally, to expand capacity demands personnel, and the disaster plan should examine measures such as expansion of staff work shift hours, call-back of off duty employees, and adapting nonclinical staff to clinical roles, as appropriate, and the development of rosters through medical societies for incorporating private physicians into staff rotation. ${ }^{[32]}$

When a defined geographic scene exists for EMS responders (it may not be in biological attacks), hospitals can arrange through the planning process to have patients decontaminated at the scene prior to transport. Even then, self-referred patients may require decontamination at the hospital. Also, when EMS personnel can only conduct gross decontamination at a scene, medical decontamination may be required at the hospital. In many countries hospitals must demonstrate a capability to decontaminate patients to achieve national accreditation, but this may involve only a few patients. ${ }^{[33]}$ Consequently, especially for mass casualty incidents, it is necessary for hospitals to develop a capability to decontaminate patients. The establishment of effective decontamination requires availability of decontamination solutions, basic shower equipment, and water containment, facility to disrobe and contain clothing and clean patient covers, and detection equipment to confirm decontamination. ${ }^{[34]}$ It is also necessary to designate and train a facility decontamination team ${ }^{[35]}$ or teams that are continuously available. The facility disaster plan should also contain prearrangements for decontamination support from local fire departments and offsite EMS personnel for incidents that produce very high numbers of contaminated patients. ${ }^{[36]}$ Finally, with many WMD agents there is a risk of secondary contamination of decontamination personnel; this issue arose during the Tokyo subway sarin release. ${ }^{[37]}$ Effective decontamination protects medical staff, but appropriate personal protective equipment is necessary to protect decontamination personnel. ${ }^{[38]}$ Depending on the agent, appropriate equipment may include special clothing as well as self-contained breathing apparatus. $^{[39]}$

Mental health consequences demand special attention in WMD terrorist incidents. These arise both for those with physical injuries and those without; it is estimated that for every single patient with a physical injury, there are 10 with some level of psychological impairment. ${ }^{[40]}$ After the September $11^{\text {th }}$ attack on New York, patients presented with psychological complaints who had only witnessed the destruction from a distance. ${ }^{[41]}$ In the majority of such cases, symptoms were transient and supportive, and crisis intervention therapy is appropriate. ${ }^{[42]}$ Trauma-related disorders are common among the physically injured ${ }^{[43]}$ although post-traumatic stress disorders also appear. ${ }^{[4+]}$ In addition to planning for psychological reactions of victims and psychological victims, it is also appropriate to consider the psychological impact on care providers. ${ }^{[45]}$ Generally, disaster plans should provide for observation and support of medical and nonmedical staff while working long shifts and for critical incident stress debriefing.

External communication capabilities are an important component of hospital disaster plans and the majority of attention is given to establishing communication links with local emergency operations centers, other hospitals, and medical institutions, EMS providers (including ambulance services), and government authorities. Intrafacility communications, however, are often not given planning attention. Common issues are that phone systems become overloaded, fixed intercom systems lack mobility, and the ability to add additional stations and radios are available in insufficient number with too few available frequencies, and cell phone nodes overload. ${ }^{[46]} \mathrm{Be}-$ cause mobility and low cost are key features of hospital disaster planning, radios are most often adopted as means of communicating within the facility. These have the added advantage that they require little training for operation and they can be shared with staff of other agencies visiting the hospital to perform support operations. ${ }^{[47]}$

\section{Training and exercises}

To function successfully, hospital disaster plans should have a training and an exercise component. Effective planning requires explaining the provisions of the plan to the administrators and personnel of those departments that will be involved in any phase of the disaster response. ${ }^{[48]}$ Furthermore, hospital disaster plan information needs to be shared with other organizations (EMS, emergency management authorities, local government, police, nongovernmental agencies, and other hospitals) that will corespond to disasters. This serves to clarify expectations for institutional performance and to identify the types of support that might be shared among responder organizations. Some personnel training focuses not just on plan provisions, but also on technical skills and knowledge. Training is consequently an integral part of the disaster planning process and successful training yields high dividends in effectiveness of emergency response. Furthermore, the training process can also become an important source of feedback regarding potential problems with the plan.

Disaster drills (exercises) provide a setting in which operational details may be critically examined. ${ }^{[49]}$ Drills also bring responding organizations into close contact and allow professionals to develop personal relationships with one another. Drills constitute a simultaneous and comprehensive test of emergency plans, staffing levels, personnel training, procedures, facilities, equipment, and materials. Finally, conducting drills serves as one form of publicity for the larger community disaster planning and management process. Publicizing drills informs both the public and community officials that planning for disasters is underway and that preparedness is being enhanced and reviewed 
One of the most important attributes of effective hospital disaster planning is that should be an ongoing process that is $\mathrm{dy}$ namic and with periodic review. ${ }^{[50]}$ In general, the plan should change to accommodate changes in the threat environment and with the introduction of new and/or improved equipment (including personal protective equipment, testing equipment, and communications). Indeed, an important benefit of the planning process is the mutual recognition and acknowledgment that there is a local response system and that those involved are mutually dependent.

\section{References}

1. Sternberg E. Planning for resilience in hospital internal disaster. Prehospita and Disaster Med 2003:18:291-9.

2. Barbera JA, Macintyre AG. Medical and health management system. Washington, DC: George Washington University; 2002.

3. Perry RW, Lindell MK. Preparedness for emergency response. Disasters 2003;27:336-50

4. Kulling PE, Holst JE. Educational and training systems in Sweden fo prehospital response to acts of terrorism. Prehosp Dis Med 2003:18:184-8.

5. Richter PV. Hospital disaster preparedness. Healthcare Facil Manag Ser 1997;8:1-11.

6. Keim ME, Pesik N, Tum-Danso NA. Lack of hospital preparedness for chemical terrorism in a major US city. Prehosp Dis Med 2003;18:193-9.

7. Kollek D. Canadian emergency department preparedness for nuclear, biological or chemical events. Can J Emerg Med 2003;5:1-14.

8. Suppe AN. Disaster management—are we ready? J Postgrad Med 1993;39:2 4.

9. Kai T, Ukai T, Onta M, Pretto E. Hospital disaster preparedness in Osaka Japan. Prehosp Dis Med 1994;9:29-34.

10. Wang $\mathrm{T}$, Chen $\mathrm{H}$, Chang $\mathrm{H}$. Hospital preparedness for weapons of mass destruction incidents. Ann Dis Med 2004:2:330-8.

11. Schreiber S, Yoeli N, Paz G, Barbash GI, Varssano D, Fertel N, Hassner A, et al. Hospital preparedness for possible nonconvential casualties: an Israeli experience. Gen Hosp Psychiatry 2004;26:359-66.

12. Perry RW, Lindell MK. Understanding human behavior in disasters with implications for terrorism. J Contingen Cri Manag 2003;11:49-61.

13. Rubin JS. Recurring pitfalls in hospital preparedness and response. J Homeland Sec 2004:2:1-15

14. Bradley RN. Health care facility preparation for weapons of mass destruction. Prehosp Emerg Care 2000;4:261-9.

15. Perry RW. Municipal terrorism management in the United States. Dis Prevent Manag 2003;12:190-202.

16. Shilotri NP, Raval MY, Hinduja IN. Gynaecological and obstetrical survey of Bhopal women following exposure to methyl isocyanate. J Postgrad Med $1986 ; 32: 203-5$

17. Morgan O. Infectious disease risks from dead bodies following natural disasters. Pan Am J Public Health 2004;15:307-12.

18. Frezza EE. The challenge of the hospitals and health care systems in preparation for biological and chemical terrorism attack. J Soc Sci 2005;1:19-24.

19. Davis, LM, Blanchard JC. Are local health responders ready for biological and chemical terrorism? Santa Monica CA: The Rand Corporation; 2002.

20. Centers for Disease Control and Prevention. Bioterrorism readiness plan: a template for healthcare facilities. Atlanta GA: Centers for Disease Control and Prevention;1999.

21. Crupi RS, Asnis DS, Lee CC, Santucci T, Marino MJ, Flantz BJ. Meeting the challenge of bioterrorism. Am J Emerg Med 2003;21:77-9.

22. Bremer R. Policy developments in disaster preparedness and management.
Prehosp Dis Med 2003;18:372-84.

23. Perry RW. Incident management systems in disaster management. Dis Prevent Manage 2003;12:405-12.

24. Macintyre AG, Christopher GW, Eitzen E Jr, Gum R, Weir S, DeAtley C, et al Weapons of mass destruction events with contaminated casualties: effective planning for healthcare facilities. JAMA 2000;283:242-9.

25. U.S. Occupational Safety and Health Administration. Hospital emergency incident command system update project. Washington DC: Occupational Safety and Health Administration; 2004.

26. Schultz $\mathrm{CH}$, Mothershead JL, Field M. Bioterrorism Preparedness. Emerg Med Clin North Am 2002;20:437-55.

27. Treat KN, Williams JM, Furbee PM, Manley WG, Russell FK, Stamper CD Jr. Hospital preparedness for weapons of mass destruction incidents: an initial assessment. Ann Emerg Med 2001;38:562-5.

28. Asai Y, Arnold JL. Terrorism in Japan. Prehosp Dis Med 2003;18:106-14.

29. Shapira SC, Shemer J. Medical management of terrorist attacks. Israeli Med Assn J 2002:4:489-92.

30. Keim M, Kaufmann AF. Principles for emergency response to bioterrorism Ann Emerg Med 1999;34:177-82.

31. Hick JL, Hanfling D, Burstein J, Barbisch D, Bogdan G, Cantrill S. Healthcare facility and community strategies for patient care surge capacity. Ann Emerg Med 2004;43:221-30.

32. Auf der Heide E. Disaster response. St Louis MO: CV Moseby Books: 1989

33. Wetter DC, Daniell WE, Treser CD. Healthcare facility preparedness for victims of chemical or biological terrorism. Am J Public Health 2001;91:710-6.

34. Koenig KL. Strip and shower: duck and cover for the 21 st century. Ann Emerg Med 2003:42:391-4

35. Hick JL, Penn P, Hanfling D, Lappe MA, O'laughlin D, Burstein JL. Establishing and training health care facility decontamination teams. Ann Emerg Med 2003:42:381-90

36. Levitin HW, Siegelson HJ, Dickinson S, Halpern P, Haraguchi Y, Nocera A, et al. Decontamination of mass casualties. Prehospital Disaster Med 2003:18:200-7.

37. Nozaki H, Hori S, Shinozawa Y, Fujishima S, Takuma K, Sagoh M, et al. Secondary exposure of medical staff to sarin vapor in the emergency room. Intens Care Med 1995:21:1032-5..

38. Horton DK, Berkowitz Z, Kaye WE. Secondary contamination of emergency department personnel from hazardous materials events. Am J Emerg Med 2003;21:199-204.

39. Georgopoulos PG, Fedele P, Shade P, Lioy PJ, Hodgson M, Longmire A, et al Hospital response to chemical terrorism: personal protective equipment training and operations planning. Am J Ind Med 2004;46:432-45.

40. Warwick MC. Psychological effects of weapons of mass destruction. Missouri Med 2002;20:11-3.

41. Boscarino JA, Figley CR, Adams RE. Fear of terrorism in New York after the September 11 terrorist attacks. Intl J Emerg Mental Health 2003:5:199-209.

42. North CS, Pfefferbaum B. Research on the mental health effects of terrorism. JAMA 2002;288:633-6.

43. Sharan P, Chaudhary G, Kavathekar SA, Saxena S. Prepliminary report of psychiatric disorders in survivors of a severe earthquake. Am J Psychiat 1996;153:556-8.

44. Galea S, Ahern J, Resnick H, Kilpatrick D, Bucuvalas M, Gold J, et al. Psychiatric sequelae of the September 11 terrorist attacks in Manhattan, New York City. N Engl J Med 2002;346:982-7.

45. Benedek DM, Holloway HC, Becker SM. Emergency mental health management in bioterrorism events. Emerg Med Clin North Am 2002:20:393-407.

46. Kenar L, Karayilanoglu T. Prehospital management and medical intervention after a chemical attack. Emerg Med J 2004;21:84-8.

47. Simon R, Teperman S. The world trade center attack: lessons for disaster management. Critical Care 2001;5:1-3

48. Tierney K, Lindell MK, Perry RW. Facing the Unexpected: Disaster Preparedness and Response in the United States. Washington DC: John Henry Press: 2001.

49. Perry RW. Disaster exercise outcomes for professional emergency personnel and citizen volunteers. J Contingen Cri Manage 2004;12:64-75.

50. Lindell MK, Perry RW. Communicating environmental risk in multiethnic communities. Thousand Oaks CA: Sage Pub; 2004. 